\title{
Talking to patients about biosimilars
}

\author{
Yelena Y Janjigian*,1, Marco Bissig²，Giuseppe Curigliano ${ }^{3}$, Jennifer Coppola ${ }^{4}$ \& Mark \\ Latymer $^{5}$ \\ ${ }^{1}$ Gastrointestinal Oncology Service, Memorial Sloan Kettering Cancer Center \& Weill Cornell Medical College, New York, NY \\ 10065, USA \\ ${ }^{2}$ Istituto di Scienze Farmacologiche della Svizzera Italiana (ISFSI), Servizio Centrale di Farmacia, Lugano, Switzerland \\ ${ }^{3}$ Division of Early Drug Development, European Institute of Oncology \& Department of Hematology Oncology, University of \\ Milano, Milan, Italy \\ ${ }^{4}$ Pfizer, Inc., New York, NY 10017, USA \\ ${ }^{5}$ Pfizer Ltd, Sandwich, Kent, UK \\ *Author for correspondence: janjigiy@mskcc.org
}

Biologic therapies target aberrant pathways in diseases including diabetes, cancer and autoimmune disorders. Despite recent scientific advances, patient access to these agents can be limited. Biosimilars are designed to be highly similar to the originator biologic, targeting the same biological pathways, with comparable efficacy and safety. Biosimilars have the advantage of lower treatment costs, offering the potential for increased clinical use and patient access. Several biosimilars are approved for clinical use in the USA and Europe; however, there is a lack of awareness about biosimilars among healthcare providers and patients. This overview of the scientific basis of biosimilars and current indications aim to enhance discussions with patients and increase understanding of the role of biosimilars in individual treatment plans.

First draft submitted: 18 January 2018; Accepted for publication: 10 May 2018; Published online: 1 June 2018

Keywords: biosimilar $\bullet$ healthcare provider $\bullet$ patient access $\bullet$ patient communication $\bullet$ regulatory pathway $\bullet$ totality of evidence

Targeted biological therapies have transformed the face of modern medicine, enhancing the treatment options available in oncology, endocrinology, rheumatology, dermatology, cardiology and nephrology [1-4]. Despite their impact on the treatment of many diseases, patient access to biologic agents may be restricted by healthcare authorities with limited resources [5-8].

As patent portfolios for biologic agents are nearing end of term, competitor manufacturers are permitted by health authorities to develop biosimilars to improve access to effective targeted agents for broader patient populations. These drugs have the potential to expand the use of biologic treatments through decreased therapy costs and increased patient access. The ultimate goal of biosimilars is to improve the efficiency of healthcare systems and overall patient outcomes $[9,10]$. Biosimilars are agents that are required to be highly similar to the originator biologic (reference product) in terms of safety, purity and efficacy [11,12]. The WHO has piloted an initiative to improve access to biologic therapies in low-income countries starting with biosimilars for rituximab (anti-CD20 antibody) for treatment of lymphoma and trastuzumab (anti-human EGFR2 antibody) for treatment of breast cancer [13].

To date, 35 biosimilars are marketed in Europe and seven biosimilars are currently licensed in the USA (Table 1) with many proposed biosimilars currently in development. As patent portfolios on many monoclonal antibody biologics are nearing end of term, the focus is moving from agents for supportive cancer care to developing biosimilars for this large product class. However, complex manufacturing systems are needed to develop these large, biological molecules, limiting their introduction to the biosimilar market to date [14,15]. Biosimilars for rituximab and bevacizumab have now been approved and the market is set to expand with the growing number of monoclonal antibody biosimilars in development [15]. In the era of biosimilars, there is a need to improve awareness of these agents to facilitate discussions between healthcare providers and patients. For instance, an international survey of patients and the general public found around half of patients diagnosed with a condition that could be treated with biologic drugs had never heard of biosimilars [16]. Healthcare providers play a crucial role in shaping 


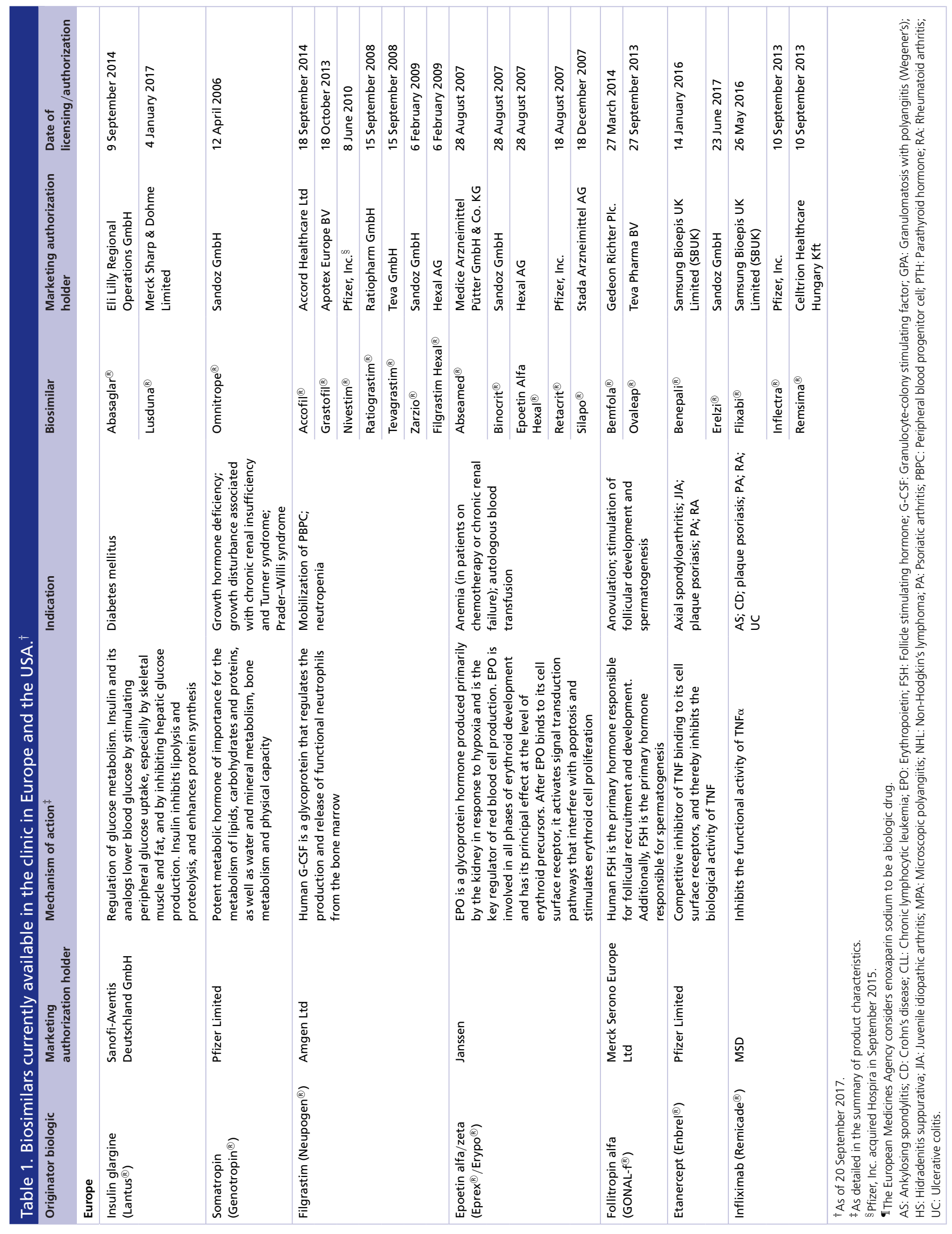




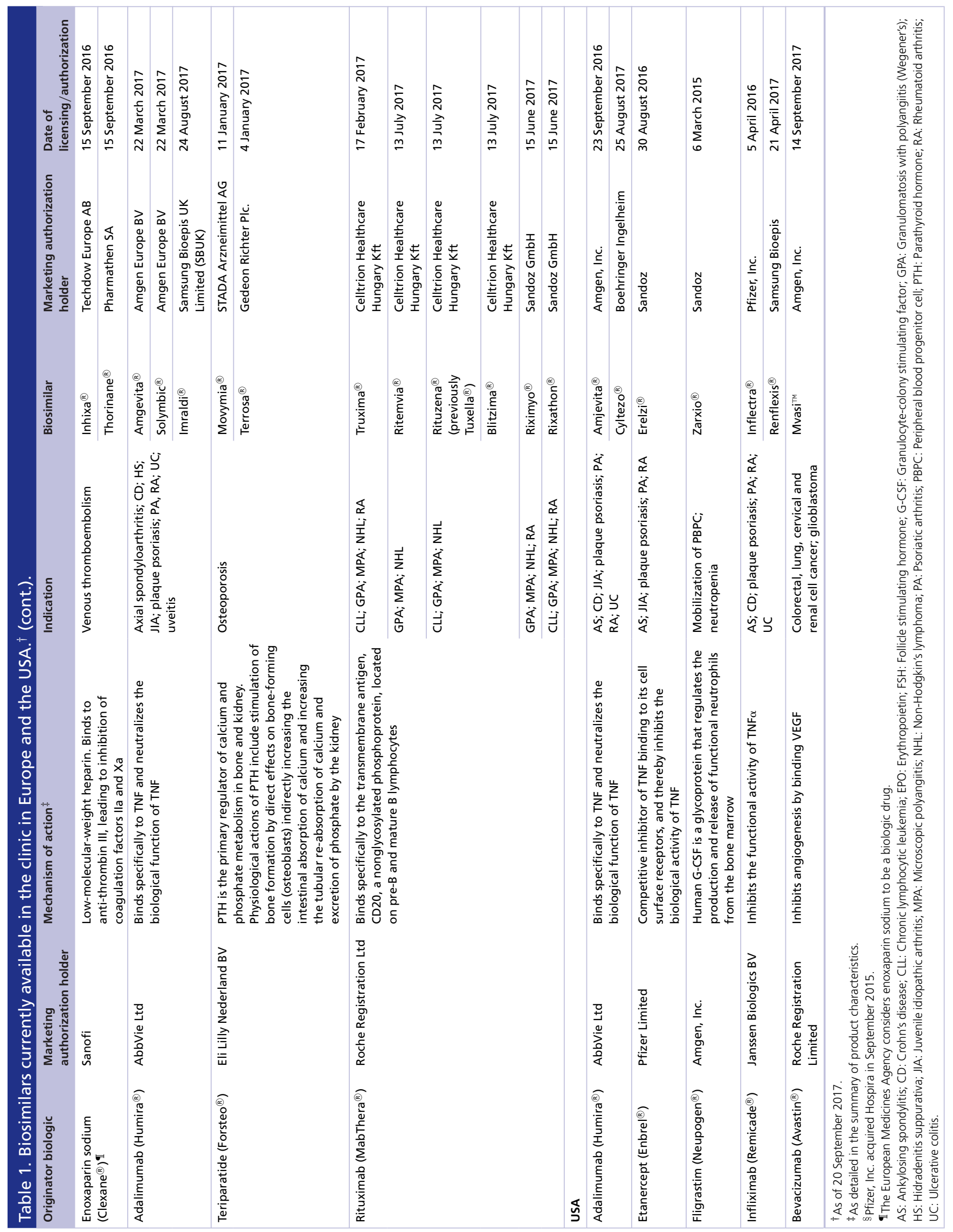


patients' perception of biosimilars and can provide appropriate information and advice. Although many are aware of biosimilars, they lack knowledge on current developments or the terminology associated with biosimilars [17,18]. Nevertheless, the majority of healthcare providers are interested in bridging this knowledge gap and incorporating biosimilars into clinical practice [17]. This review aims to enhance the level of understanding of healthcare providers on various aspects of biosimilars to better equip them when communicating with patients concerning treatment with biosimilars.

\section{Understanding biosimilars}

In comparison to chemically synthesized small molecule drugs, biologic therapies (such as monoclonal antibodies) are generated in biological systems and are therefore structurally complex and inherently more variable [19,20]. The overall structure of a biologic drug is defined by its primary amino acid sequence. To qualify as a biosimilar, one requirement is that the primary amino acid sequence must be identical to the originator biologic. Variations in the higher order structure of the protein can impact the function, immunogenicity and efficacy of the biologic product, so any differences in higher order protein structure between the biosimilar and originator biologic are extensively analyzed to determine that they are not expected to be clinically relevant [19-21].

As manufacturing conditions for biosimilars are complex, the biochemical and higher order structural characteristics of the biosimilar will not be identical to the originator biologic. This is in contrast to generic versions of small molecule drugs, which have an identical structure, stability and purity to the originator. Biosimilars, therefore, should not be considered as generic versions of biologic drugs [22].

Understanding that complexity and heterogeneity is inherent to all biologic drugs, and is not limited to biosimilars, highlights that biosimilars are intrinsically no more variable than originator biologics and there is no impact on the efficacy and safety of biosimilars compared with originator products [23]. A better awareness of the production and manufacturing process of biosimilars may address common misconceptions, such as biosimilars being generic versions of biologic drugs [23].

\section{Biosimilar regulation: quality, safety \& efficacy}

To obtain regulatory approval, biosimilars must be 'highly similar' with regard to their structural and functional characteristics, and have similar pharmacokinetic, efficacy and safety profiles compared with the originator biologic $[11,12,24]$. As the manufacturing process is complex, biosimilars are 'highly similar' but not identical to the originator biologic, thus the small molecule generic drug approval process cannot be applied to biosimilars [25,26]. Regulatory requirements for biosimilar approval are broadly consistent across regulatory agencies, such as the EMA and US FDA [11,12]; however, each submission is generally assessed on a case-by-case basis. Biosimilar developers collaborate with regulatory agencies to establish the appropriate analytical, nonclinical and clinical studies required to demonstrate biosimilarity and to establish the evidence base needed to support the approval of biosimilars [11,12,24].

Biosimilar approval is based on a rigorous stepwise process of comparison with the originator biologic (Figure 1). In contrast to the development of biologic drugs, a considerable proportion of the evidence is based on structural and physiochemical assessments of the biosimilar. The demonstration of high structural and functional similarity to the originator biologic reduces the extent of additional nonclinical and clinical studies that must be performed [24]. The regulatory pathway for originator biologics includes an extensive clinical trial program to support approval. For biosimilars, data from each step of the biosimilar regulatory pathway are considered important, comprising analytical and preclinical data, comparative pharmacokinetics, and efficacy and safety in a relevant therapeutic indication known as the totality of evidence [11,12,15,24-26].

Initially, analytical studies are performed to demonstrate structural similarity (i.e., identical amino acid sequence and similar higher order structure) and functional similarity. If necessary, these are followed by animal studies to assess in vivo bioactivity and toxicity [28]. Lastly, a tailored head-to-head clinical trial program is conducted to compare the pharmacokinetics, clinical efficacy, clinical safety and immunogenicity of the biosimilar and originator biologic. Aspects of the trial design, such as end points and sample size, may differ compared with those needed for approval of the originator biologic [6,26]. While originator biologics are usually assessed in controlled trials designed to show superiority $[6,26]$, the purpose of biosimilar clinical trials is to establish proof of quality and similarity regarding pharmacokinetics and efficacy. Biosimilar clinical trials are also designed to address any remaining concerns about product-related differences between the biosimilar and the originator biologic $[6,15,26]$.

Regulatory guidelines require that data from a number of comparative in vitro tests are supplied to assess any potential differences in the activity of the biosimilar compared with the originator biologic [29]. The number of 


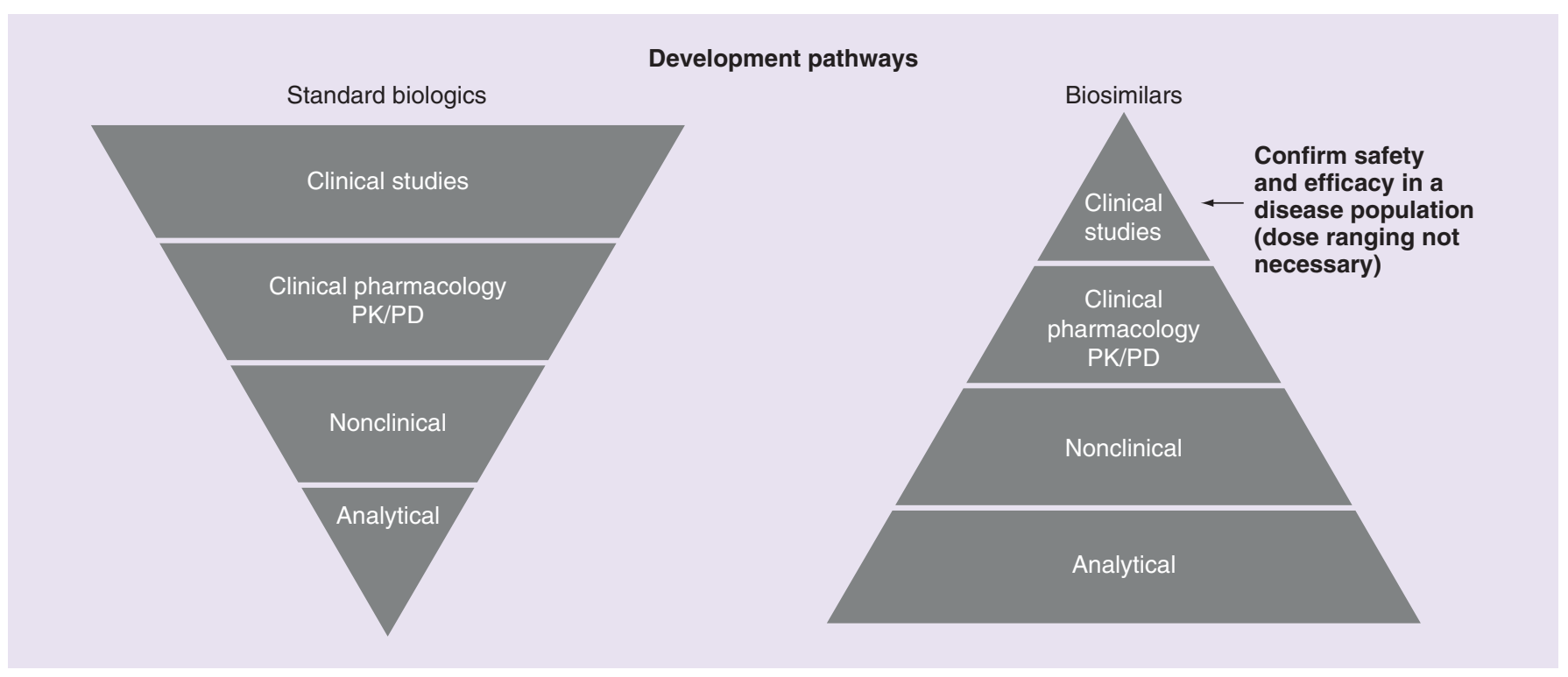

Figure 1. Summary of the biosimilar and standard biologic approval pathways.

PD: Pharmacodynamic; PK: Pharmacokinetic.

Adapted with permission from [27].

tests required will depend on the batch-to-batch variability of the biosimilar and originator biologic. Biosimilars have the same dosing schedule and route of administration as the originator biologic; however, differences in the formulation, presentation and method of administration of the biosimilar may be allowed if there is no effect on the safety and efficacy of the drug [30]. Once the similarity of a biosimilar to its originator biologic has been demonstrated, a biosimilar can be approved for use in other eligible clinical indications that the originator biologic is approved for [31]. However, this extrapolation of safety and efficacy data is not automatically guaranteed; it is based on the totality of the evidence supporting biosimilarity and scientific justification, in which substantiation of the mechanism of action and pharmacokinetics, being the same across indications, are key components.

The term 'interchangeability' is widely used but can have a different meaning depending on the country and jurisdiction, and is also often used incorrectly when the topic under discussion is actually 'switching'. In the EU, there is no regulatory definition of interchangeability and the term refers only 'to the possibility of exchanging one medicine for another medicine that is expected to have the same clinical effect' [30]. EU member states set individual policies on switching and other prescribing practices, and most countries have decided that automatic substitution without the intervention of the prescriber is inappropriate for biologics, including biosimilars [32]. Interchangeability is defined by statute in the USA to mean that 'the biological product may be substituted for the reference product without the intervention of the healthcare provider who prescribed the reference product', and this would enable pharmacy-mediated substitution, where state laws allow [33,34]. However, this requires an additional standard to biosimilarity defined in the statute and the FDA is currently drafting guidance on Considerations in Demonstrating Interchangeability with a Reference Product [34,35]. Consequently, to avoid confusion across geographies, we have chosen to refer specifically to 'switching' and 'substitution' in this paper, to ensure consistency of language and meaning.

As with all biologics, it is critical to monitor the safety of biosimilars on an ongoing basis after approval. Thus, any additional specific safety monitoring for the originator biologic also applies to the biosimilar $[6,15,26]$. For example, the British Society for Rheumatology Biologics Register collects information on the biosimilars Benepali ${ }^{\circledR}$, Inflectra ${ }^{\circledR}$ and Remsima ${ }^{\circledR}$ to ensure that the data on adverse events are as robust as those collected for the originator biologics [36]. The evidence available from both the regulatory assessment and postmarketing surveillance has shown biosimilars to have comparable efficacy and safety profiles to the originator biologic products [10,37-44]. For example, Retacrit ${ }^{\circledR}$, a biosimilar to Eprex ${ }^{\circledR}$, a human recombinant epoetin, has demonstrated efficacy in treating anemia associated with chronic renal failure or chemotherapy for solid tumors, malignant lymphoma or multiple myeloma. Up to May 2016, the estimated postmarketing exposure for EU-approved Retacrit ${ }^{\circledR}$ was approximately 323,000 
Table 2. How biosimilars have expanded use in Europe.

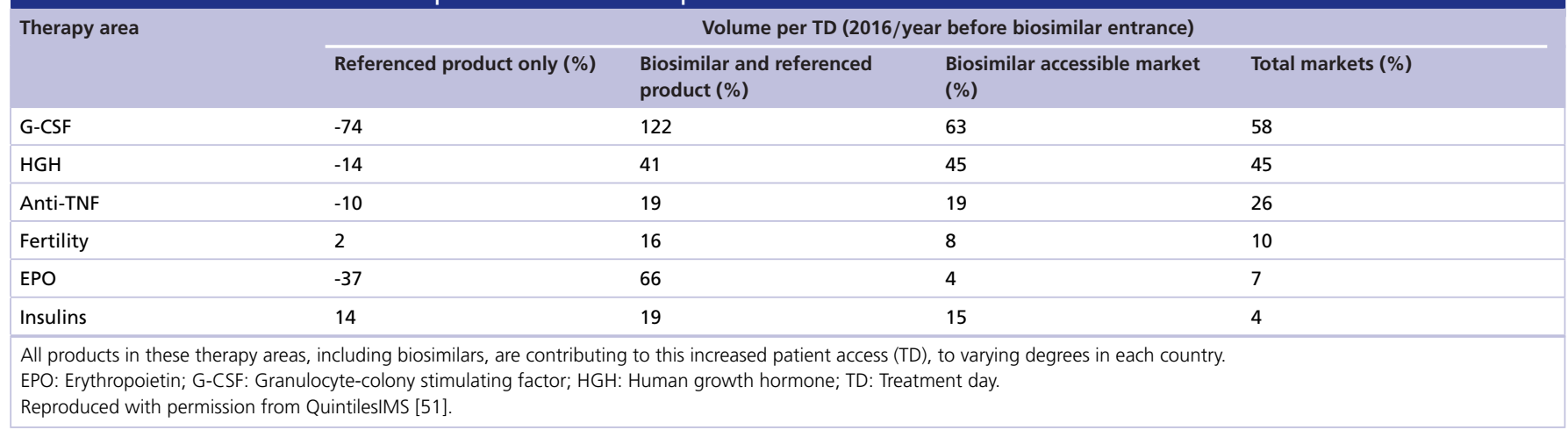

patient-years, and the safety profile is consistent with that seen for the originator biologic [45]. The safety and efficacy of biosimilars for erythropoiesis-stimulating agents and granulocyte-colony stimulating factor (G-CSF) has also been demonstrated in supportive cancer care in real-world clinical practice settings [38,46].

Although the data required for biosimilar approval differ from those required for originator biologics and small molecule generic drugs, the same high standards of safety and efficacy still apply. This ensures that when used in clinical practice, biosimilars are expected to be as safe and effective as the originator biologic. Providing information on the development and regulatory approval pathway of biosimilars may help address common concerns patients have surrounding the safety, efficacy and quality of biosimilars [16,23].

\section{Expanding patient access}

Biosimilars have the potential to expand patient access to biologic medicines as possible treatment options across a number of life-threatening and chronic diseases. In addition, biosimilars could provide savings and efficiencies for healthcare systems. However, these savings are not expected to be on the same level as those seen for generic drugs, as these smaller chemical products are easier to characterize, and it is usually sufficient to demonstrate structural and pharmacokinetic similarity to achieve regulatory approval [26]. Typically, production of a generic drug can take 3-5 years at a cost of US $\$ 1-5$ million; this is in contrast to the 8-10 years it can take to develop a biosimilar at an estimated cost of US\$100-200 million [47]. Biosimilars are less costly to produce compared with originator biologics as the development process is designed to establish bioequivalence to the originator product in a relevant patient population, and it is not necessary to re-establish efficacy for every indication for which the originator product is approved $[48,49]$. Additionally, the introduction of biosimilars at a lower price than the originator biologic can promote price competition within the product market [48-51]. Following the introduction of biosimilars in Europe, increased competition has not only affected the price of the originator biologic but also the product class, resulting in a fall in average prices within the total market [51]. In 2016, compared with the price before the corresponding biosimilar was available, reductions of $4-27 \%$ were reported in the following therapy areas: epoetins, G-CSF, fertility, human growth hormone and anti-TNF [51]. In the USA, it has been projected that biosimilars will lead to a US $\$ 44.2$ billion reduction in biologic spending over a 10 -year period, based on an estimated 35\% price reduction [48]. A budget analysis of the rituximab biosimilar CT-P10 in European countries has estimated projected savings of $€ 56.82$ million over a 1-year period (for treatment of non-Hodgkin's lymphoma and chronic lymphocytic leukemia). This would expand patient access to rituximab treatment for an additional 2263 patients with non-Hodgkin's lymphoma and 1624 patients with chronic lymphocytic leukemia [52].

Although uptake varies by product class and country, the introduction of biosimilars has increased patient access to therapies across whole product classes in Europe (Table 2) [51]. This increase, in use of both the biosimilar and originator biologic, ranges from $16 \%$ for fertility drugs to $122 \%$ for G-CSFs [51]. In particular, the availability of biosimilar G-CSF has led to increased G-CSF usage in both Sweden and the UK [38]. The benefits of biosimilars can go beyond the potential for healthcare cost savings and can have an effect on patient treatment overall. Increased access to treatment, due to the availability of biosimilars, may enable physicians to adhere more closely to clinical treatment guidelines or result in patients receiving treatment earlier in the course of their disease [38]. For example, in a retrospective cohort study following switching of patients from originator to biosimilar filgrastim, a higher proportion of patients received treatment for primary prophylaxis in the biosimilar cohort than those in the 
originator filgrastim cohort [53]. Patients may also benefit from more detailed examination during treatment; for example, therapeutic drug monitoring has been used in patients with inflammatory bowel disease to guide decisions regarding treatment withdrawal or switching to biosimilars [54,55].

\section{Talking to patients}

Patients may have concerns about receiving or switching to biosimilar treatment; they may have questions about how safe the biosimilar is, whether it will be as effective as the originator biologic or if the biosimilar delivery device differs in design and use $[16,23,56,57]$. The impact of 'nocebo' effects, whereby negative expectations of treatment lead to potentially worse outcomes, also needs to be considered by healthcare providers [58,59]. These effects are unrelated to the pharmacology of the drug, in that patients may simply perceive that a drug is less expensive because it is less effective [60]. Enhanced communication by healthcare providers, for example, using 'soft skills', can alleviate patient concerns. This strategy has proved successful in patients switching to biosimilars, with fewer patients discontinuing treatment compared with patients transitioning without an enhanced communication strategy [61]. The Danish Rheumatism Association has designed a national program to reassure patients about the safety of biosimilars by providing independent information to patients and healthcare providers, along with improved monitoring of prescriptions, such as providing easier ways to report side effects [62]. In future, a patient representative from the Danish Rheumatism Association will be included on working groups for national recommendations on biologic drugs and biosimilars to ensure that patient perspectives are included [62]. A recent review of biosimilars suggests that healthcare providers should not prevent patients from switching to treatment with biosimilars due to concerns about potential risks, as these are outweighed by expanding patient access to treatment [63].

It is important that healthcare providers fully understand biosimilars so that they have an increased confidence in prescribing them $[17,64]$. Various resources are currently available to assist with education regarding biosimilars and to support discussions with patients (Table 3). These include: up-to-date evidence on the science behind biosimilars, regulatory requirements, typical questions that patients may have about treatment, video discussions with clinical experts and support from patient advocacy groups [16,23]. The American Society of Oncology and the European Society for Medical Oncology have both issued position statements to guide healthcare providers on the use of biosimilars in oncology settings [34,65]. Providing guidance for healthcare providers will ensure that decisions on biosimilar treatment are in the best interests of patients.

Healthcare providers are encouraged to have open discussions with patients about biosimilars and avoid using overly technical language and medical jargon [66,67]. In order to increase the acceptance of biosimilars, there is still a need for further materials and policies to better inform healthcare providers and patients [64,68]. In our opinion, it is important to increase awareness about 'biosimilarity' of the originator biologic and the biosimilar. The basis for regulatory approval of biosimilars is in demonstrating similarity between short-term end points within a narrow margin to avoid repetition of the costly and larger trials required for approval of the originator biologic. Patients should understand this concept in order to avoid the perception of a biosimilar as an 'inferior drug'. Information should be provided in a consistent and clear manner across resources, with access/links to further reading materials. Integration of biosimilars into national and local policies for prescribing medicines could lead to improved education and awareness of biosimilars, allowing healthcare providers and patients to have more informed discussions and share decision making about treatment with biosimilars.

\section{Summary}

Biologics have shaped the therapeutic approach to human disease. Introducing high-quality, safe and effective biosimilars could potentially expand patient access to these important medicines by broadening the number of treatment options available and providing savings to healthcare systems. Healthcare providers can have a large impact on a patient's perception of biosimilars, and are a key source of information and advice for patients. Full use should be made of the many additional resources available, such as online educational materials and information from patient associations, to help inform patients and facilitate discussions about biosimilars between patients and healthcare providers.

\section{Future perspective}

There is a growing number of biosimilars of originator biologics receiving regulatory approval, or in the late stages of development, in Europe and the USA. Healthcare providers will therefore increasingly encounter biosimilars as potential treatment options to consider for their patients across a number of chronic or life-threatening diseases. 
Review Janjigian, Bissig, Curigliano, Coppola \& Latymer

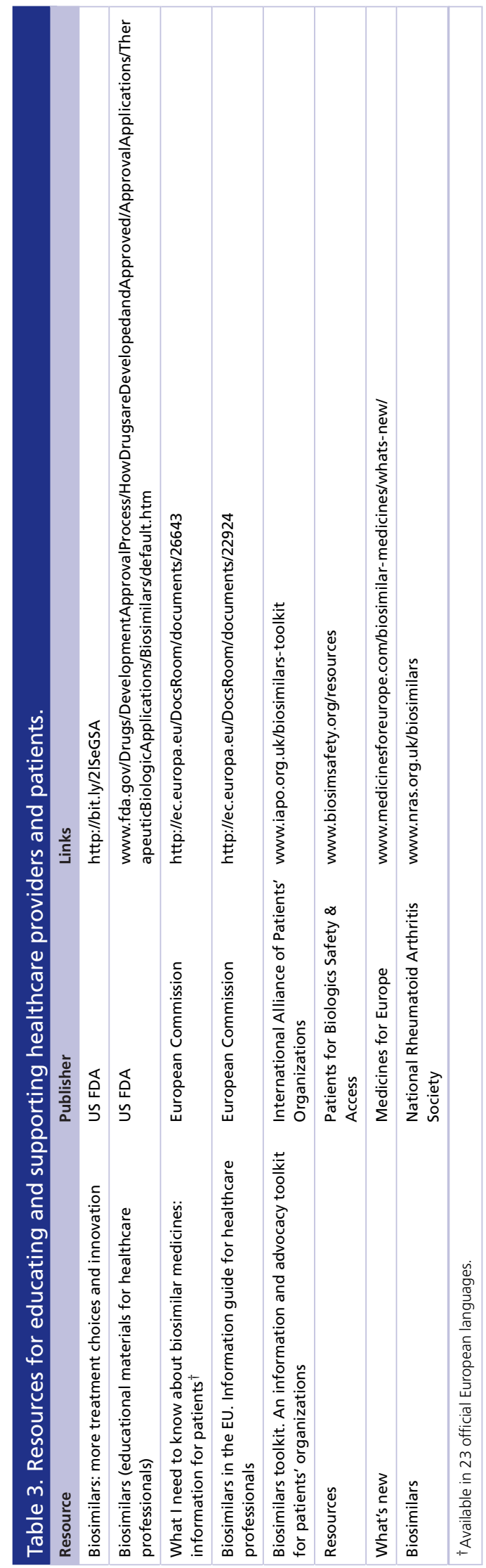


The range of educational resources on biosimilars is also likely to increase, which could help healthcare providers to become more confident when prescribing biosimilars. Improved educational resources and initiatives will increase understanding and ensure the most appropriate use of biosimilars, with the likelihood of improved overall patient outcomes, through increased access, and healthcare system benefits. This, in turn, will help healthcare providers to be more fully informed when discussing an expanding range of options for patients starting or switching to biosimilar treatment.

\section{Executive summary}

- Despite biologic therapies enhancing the range of available treatment options in a number of chronic diseases, patient access to these therapies can be limited.

- Patent portfolios for biologic therapies are nearing end of term, permitting drug companies to develop biosimilars.

- There is a lack of awareness, among both healthcare providers and patients, about treatment with biosimilars.

Understanding biosimilars

- Biosimilars are highly similar to the originator biologic in terms of safety, purity and efficacy.

- The primary amino acid sequence is required to be identical to the originator biologic; however, biochemical and higher order structural characteristics of the biosimilar may be different, although these differences are not considered to impact clinical efficacy and safety.

- Biosimilars are not generic versions of biologic drugs.

Biosimilar regulation: quality, safety \& efficacy

- Biosimilar approval is based on assessment of the totality of the evidence: including analytical and preclinical data, comparative pharmacokinetics, and efficacy and safety information.

- This stepwise regulatory approach ensures that biosimilars are expected to be as safe and effective as the originator biologic when used in clinical practice.

Expanding patient access

- Through price competition in product markets and reduced development costs, biosimilars have the potential to expand patient access by providing savings for healthcare systems.

Talking to patients

- Patients may have a number of concerns about starting or switching to biosimilar treatment.

- A wide range of educational resources is available to improve awareness of biosimilars.

Summary

- Healthcare providers are a key source of information and advice for patients and have an important role in determining a patient's perception of biosimilars.

- Improved awareness of biosimilars could lead to more effective and better informed discussions between healthcare providers and patients on patient treatment plans.

Financial \& competing interests disclosure

YY Janjigian has received research funding from Boehringer Ingelheim, Bayer, Genentech, Bristol-Myers Squibb, Eli Lilly, Pfizer and Merck and served as a Scientific Advisor to Merck Serono, Astellas, Eli Lilly and Bristol-Myers Squibb. M Bissig has no potential conflicts of interest to declare. G Curigliano has received speaker fees from Pfizer, Inc. J Coppola and M Latymer are employees and shareholders of Pfizer, Inc. The authors have no other relevant affiliations or financial involvement with any organization or entity with a financial interest in or financial conflict with the subject matter or materials discussed in the manuscript apart from those disclosed.

Writing assistance was utilized in the production of this manuscript. Medical writing support was provided by J Oliver and AM McGonigal of Engage Scientific Solutions and was funded by Pfizer, Inc.

\section{Open access}

This work is licensed under the Attribution-NonCommercial-NoDerivatives 4.0 Unported License. To view a copy of this license, visit http://creativecommons.org/licenses/by-nc-nd/4.0/

\section{References}

Papers of special note have been highlighted as: $\bullet$ of interest; $\bullet \bullet$ of considerable interest

1. Tinoco G, Warsch S, Glück S, Avancha K, Montero AJ. Treating breast cancer in the 21 st century: emerging biological therapies. J. Cancer 4(2), 117-132 (2013). 
2. Conti F, Ceccarelli F, Massaro L et al. Biological therapies in rheumatic diseases. Clin. Ter. 164(5), e413-e428 (2013).

3. Holdsworth SR, Gan PY, Kitching AR. Biologics for the treatment of autoimmune renal diseases. Nat. Rev. Nephrol. 12(4), 217-231 (2016).

4. Leonardi CL, Romiti R, Tebbey PW. Ten years on: the impact of biologics on the practice of dermatology. Dermatol. Clin. 33(1), $111-125$ (2015).

5. Baer Ii WH, Maini A, Jacobs I. Barriers to the access and use of rituximab in patients with non-Hodgkin's lymphoma and chronic lymphocytic leukemia: a physician survey. Pharmaceuticals 7(5), 530-544 (2014).

6. Socinski MA, Curigliano G, Jacobs I, Gumbiner B, MacDonald J, Thomas D. Clinical considerations for the development of biosimilars in oncology. $m A b s$ 7(2), 286-293 (2015).

7. Lammers P, Criscitiello C, Curigliano G, Jacobs I. Barriers to the use of trastuzumab for HER2+ breast cancer and the potential impact of biosimilars: a physician survey in the United States and emerging markets. Pharmaceuticals 7(9), 943-953 (2014).

8. Monk BJ, Lammers PE, Cartwright T, Jacobs I. Barriers to the access of bevacizumab in patients with solid tumors and the potential impact of biosimilars: a physician survey. Pharmaceuticals 10(1), E19 (2017).

9. McCamish M, Woollett G. The state of the art in the development of biosimilars. Clin. Pharmacol. Ther. 91(3), 405-417 (2012).

10. Bennett CL, Chen B, Hermanson T et al. Regulatory and clinical considerations for biosimilar oncology drugs. Lancet Oncol. 15(13), e594-e605 (2014).

11. Guideline on similar biological medicinal products. www.ema.europa.eu/docs/en_GB/document_library/Scientific_guideline/2014/10/WC500176768.pdf

12. Scientific considerations in demonstrating biosimilarity to a reference product: guidance for industry. www.fda.gov/downloads/Drugs/GuidanceComplianceRegulatoryInformation/Guidances/UCM291128.pdf

13. WHO to begin pilot prequalification of biosimilars for cancer treatment. www.who.int/mediacentre/news/releases/2017/pilot-prequalification-biosimilars/en/

14. Moorkens E, Jonker-Exler C, Huys I, Declerck P, Simoens S, Vulto AG. Overcoming barriers to the market access of biosimilars in the European Union: the case of biosimilar monoclonal antibodies. Front. Pharmacol. 7, 193 (2016).

15. Rugo HS, Linton KM, Cervi P, Rosenberg JA, Jacobs I. A clinician's guide to biosimilars in oncology. Cancer Treat. Rev. 46, 73-79 (2016).

-• Offers guidance for oncology practitioners on how to evaluate data on biosimilars when using these drugs in clinical practice and reviews several biosimilars which are currently being developed for treating cancer.

16. Jacobs I, Singh E, Sewell KL, Al-Sabbagh A, Shane LG. Patient attitudes and understanding about biosimilars: an international cross-sectional survey. Patient Prefer. Adherence 10, 937-948 (2016).

- Presents results from an international survey assessing the levels of awareness, usage and knowledge of biosimilars among patients, caregivers and the general population in the USA and Europe.

17. Zelenetz AD, Ahmed I, Braud EL et al. NCCN Biosimilars White Paper: regulatory, scientific, and patient safety perspectives. J. Natl Compr. Canc. Netw. 9(Suppl. 4), S1-S22 (2011).

18. Cohen H, Beydoun D, Chien D et al. Awareness, knowledge, and perceptions of biosimilars among specialty physicians. Adv. Ther. 33(12), 2160-2172 (2017).

-• Assesses the current levels of awareness, knowledge and perceptions of biosimilars among USA specialty physicians who prescribe biologics, highlighting the main areas where knowledge gaps exist.

19. Crommelin D, Bermejo T, Bissig M et al. Pharmaceutical evaluation of biosimilars: important differences from generic low-molecular-weight pharmaceuticals. Eur. J. Hosp. Pharm. Sci. 11(1), 11-17 (2005).

20. Berkowitz SA, Engen JR, Mazzeo JR, Jones GB. Analytical tools for characterizing biopharmaceuticals and the implications for biosimilars. Nat. Rev. Drug Discov. 11(7), 527-540 (2012).

21. Kuhlmann M, Covic A. The protein science of biosimilars. Nephrol. Dial. Transplant. 21(Suppl. 5), v4-v8 (2006).

22. Declerck P, Danesi R, Petersel D, Jacobs I. The language of biosimilars: clarification, definitions, and regulatory aspects. Drugs $77(6)$, 671-677 (2017).

23. Peyrin-Biroulet L, Lönnfors S, Roblin X, Danese S, Avedano L. Patient perspectives on biosimilars: a survey by the European Federation of Crohn's and Ulcerative Colitis Associations. J. Crohns Colitis 11(1), 128-133 (2017).

- Presents results from a survey of patients revealing the common concerns they have about treatment with biosimilars.

24. Guidelines on evaluation of similar biotherapeutic products (SBPs). www.who.int/biologicals/areas/biological_therapeutics/BIOTHERAPEUTICS_FOR_WEB_22APRIL2010.pdf

25. Weise M, Bielsky MC, De Smet K et al. Biosimilars-why terminology matters. Nat. Biotechnol. 29(8), 690-693 (2011).

26. Weise M, Bielsky MC, De Smet K et al. Biosimilars: what clinicians should know. Blood 120(26), 5111-5117 (2012). 
27. Kozlowski S. Biosimilar biological products: overview of approval pathway under the Biologics Price Competition and Innovation Act of 2009 (2012). https://wayback.archive-it.org/7993/20170405225927/www.fda.gov/downloads/AdvisoryCommittees/CommitteesMeet ingMaterials/Drugs/AdvisoryCommitteeforPharmaceuticalScienceandClinicalPharmacology/UCM315764.pdf

28. Chapman K, Adjei A, Baldrick P et al. Waiving in vivo studies for monoclonal antibody biosimilar development: national and global challenges. $m A$ s 8 (3), 427-435 (2016).

29. European Medicines Agency. Guideline on similar biological medicinal products containing biotechnology-derived proteins as active substance: non-clinical and clinical issues. www.ema.europa.eu/docs/en_GB/document_library/Scientific_guideline/2015/01/WC500180219.pdf

30. European Medicines Agency. Biosimilars in the EU: information guide for healthcare professionals. www.ema.europa.eu/docs/en_GB/document_library/Leaflet/2017/05/WC500226648.pdf

31. Schellekens H, Lietzan E, Faccin F, Venema J. Biosimilar monoclonal antibodies: the scientific basis for extrapolation. Expert Opin. Biol. Ther. 15(11), 1633-1646 (2015).

32. Niederwieser D, Schmitz S. Biosimilar agents in oncology/haematology: from approval to practice. Eur. J. Haematol. 86(4), 277-288 (2011).

33. US FDA. Title VII - improving access to innovative medical therapies. Subtitle A - Biologics Price Competition and Innovation Act of 2009. www.fda.gov/downloads/Drugs/GuidanceComplianceRegulatoryInformation/UCM216146.pdf

34. Lyman GH, Balaban E, Diaz M et al. American Society of Clinical Oncology Statement: biosimilars in oncology. J. Clin. Oncol. 36(12), 1260-1265 (2018).

35. US FDA. Considerations in demonstrating interchangeability with a reference product. Guidance for industry. www.fda.gov/downloads/Drugs/GuidanceComplianceRegulatoryInformation/Guidances/UCM537135.pdf

36. Biologics registers. www.rheumatology.org.uk/Knowledge/Registers

37. Braun J, Kudrin A. Switching to biosimilar infliximab (CT-P13): evidence of clinical safety, effectiveness and impact on public health. Biologicals 44(4), 257-266 (2016).

38. Gascon P, Tesch H, Verpoort K et al. Clinical experience with Zarzio ${ }^{\circledR}$ in Europe: what have we learned? Support. Care Cancer 21(10), 2925-2932 (2013).

39. Schellekens H, Smolen JS, Dicato M, Rifkin RM. Safety and efficacy of biosimilars in oncology. Lancet Oncol. 17(11), e502-e509 (2016).

-. Reviews the safety and efficacy of biosimilars in oncology, including issues on interchangeability and extrapolation of biosimilars to other disease and patient indications.

40. Dorner T, Strand V, Cornes P et al. The changing landscape of biosimilars in rheumatology. Ann. Rheum. Dis. 75(6), 974-982 (2016).

41. Jahnsen J. Clinical experience with infliximab biosimilar Remsima (CT-P13) in inflammatory bowel disease patients. Therap. Adv. Gastroenterol. 9(3), 322-329 (2016).

42. Ahmed I, Kaspar B, Sharma U. Biosimilars: impact of biologic product life cycle and European experience on the regulatory trajectory in the United States. Clin. Ther. 34(2), 400-419 (2012).

43. Abraham I, Macdonald K. Clinical safety of biosimilar recombinant human erythropoietins. Expert Opin. Drug Saf. 11(5), 819-840 (2012).

44. Jørgensen KK, Olsen IC, Goll GL et al. Switching from originator infliximab to biosimilar CT-P13 compared with maintained treatment with originator infliximab (NOR-SWITCH): a 52-week, randomised, double-blind, non-inferiority trial. Lancet 389(10086), 2304-2316 (2017).

45. US FDA. FDA Advisory Committee Briefing Document. Epoetin Hospira. www.fda.gov/downloads/advisorycommittees/committeesm eetingmaterials/drugs/oncologicdrugsadvisorycommittee/ucm559968.pdf

46. Trotta F, Belleudi V, Fusco D et al. Comparative effectiveness and safety of erythropoiesis-stimulating agents (biosimilars vs originators) in clinical practice: a population-based cohort study in Italy. BMJ Open 7(3), e011637 (2017).

47. Hirsch BR, Balu S, Schulman KA. The impact of specialty pharmaceuticals as drivers of health care costs. Health Aff. 33(10), 1714-1720 (2014).

48. Mulcahy AW, Predmore Z, Mattke S. The cost savings potential of biosimilar drugs in the United States. RAND Corporation (2014). www.rand.org/content/dam/rand/pubs/perspectives/PE100/PE127/RAND_PE127.pdf

49. Blackstone EA, Joseph PF. The economics of biosimilars. Am. Health Drug Benefits 6(8), 469-478 (2013).

50. Singh SC, Bagnato KM. The economic implications of biosimilars. Am. J. Manag. Care 21(Suppl. 16 ), s331-s340 (2015).

51. Medicines for Europe. The impact of biosimilar competition in Europe. www.medicinesforeurope.com/wp-content/uploads/2017/05/IMS-Biosimilar-2017_V9.pdf

52. Gulacsi L, Brodszky V, Baji P, Rencz F, Pentek M. The rituximab biosimilar CT-P10 in rheumatology and cancer: a budget impact analysis in 28 European countries. Adv. Ther. 34(5), 1128-1144 (2017). 
53. Verpoort K, Mohler TM. A non-interventional study of biosimilar granulocyte colony-stimulating factor as prophylaxis for chemotherapy-induced neutropenia in a community oncology centre. Ther. Adv. Med. Oncol. 4(6), 289-293 (2012).

54. Hoseyni $\mathrm{H}, \mathrm{Xu}$ Y, Zhou H. Therapeutic drug monitoring of biologics for inflammatory bowel disease: an answer to optimized treatment? J. Clin. Pharmacol. 58(7), 864-876 (2018).

55. Schmitz EMH, Benoy-De Keuster S, Meier AJL et al. Therapeutic drug monitoring (TDM) as a tool in the switch from infliximab innovator to biosimilar in rheumatic patients: results of a 12-month observational prospective cohort study. Clin. Rheumatol. 36(9), 2129-2134 (2017).

56. Wilkins AR, Venkat MV, Brown AS et al. Patient perspectives on biosimilar insulin. J. Diabetes Sci. Technol. 8(1), 23-25 (2014).

57. Sullivan E, Piercy J, Waller J, Black CM, Kachroo S. Assessing gastroenterologist and patient acceptance of biosimilars in ulcerative colitis and Crohn's disease across Germany. PLoS ONE 12(4), e0175826 (2017).

58. Planès S, Villier C, Mallaret M. The nocebo effect of drugs. Pharmacol. Res. Perspect. 4(2), e00208 (2016).

59. Rezk MF, Pieper B. Treatment outcomes with biosimilars: be aware of the nocebo effect. Rheumatol. Ther. 4(2), $209-218$ (2017).

60. Waber RL, Shiv B, Carmon Z, Ariely D. Commercial features of placebo and therapeutic efficacy. JAMA 299(9), 1016-1017 (2008).

61. Tweehuysen L, Huiskes V, Van Den Bemt B, Van Den Hoogen F, Den Broeder A. FRI0200 Higher acceptance and persistence rates after biosimilar transitioning in patients with a rheumatic disease after employing an enhanced communication strategy. Ann. Rheum. Dis. 76(Suppl. 2), 557 (2017).

- Highlights the impact of enhanced patient engagement on treatment acceptance and persistence rates in patients transitioning to biosimilar treatment.

62. Thomsen L. OP0328-PARE patient safety in relation to biosimilars - how can we act as a patient organization? Ann. Rheum. Dis. 76(Suppl. 2), 190-191 (2017).

63. Inotai A, Prins CPJ, Csanadi M, Vitezic D, Codreanu C, Kalo Z. Is there a reason for concern or is it just hype? - A systematic literature review of the clinical consequences of switching from originator biologics to biosimilars. Expert Opin. Biol. Ther. 17(8), 915-926 (2017).

64. Ventola CL. Biosimilars: part 2: potential concerns and challenges for P\&T committees. P T 38(6), 329-335 (2013).

65. Tabernero J, Vyas M, Giuliani R et al. Biosimilars: a position paper of the European Society for Medical Oncology, with particular reference to oncology prescribers. ESMO Open 1(6), e000142 (2016).

66. Health literacy and patient safety: help patients understand. http://med.fsu.edu/userFiles/file/ahec_health_clinicians_manual.pdf

67. Graham S, Brookey J. Do patients understand? Perm. J. 12(3), 67-69 (2008).

68. Skingle D. Biosimilars: what do patients need to consider? RMD Open 1(1), e000141 (2015). 